\title{
Bacteriophage infections of microbiota can lead to leaky gut in an experimental rodent model
}

\author{
George Tetz ${ }^{*}$ and Victor Tetz
}

\begin{abstract}
Increased intestinal permeability and translocation of gut microbiota from the intestinal lumen to the systemic circulation predispose patients to various diseases and may be one of the main triggers thereof. The role of microbiota in increased intestinal permeability is under intensive investigation. Here, we studied alterations in the host and increased intestinal permeability as a direct effect of treatment with a bacteriophage cocktail. After 10 days of challenge, the rats showed weight loss, messy hair, and decreased activity. Additionally, they displayed a significantly elevated lactulose:mannitol ratio and the level of circulating immune complexes. To our knowledge, this study demonstrates for the first time that increased intestinal permeability may be induced by bacteriophages that affect the microbiota.
\end{abstract}

Keywords: Bacteriophage, Intestinal permeability, Microbiota

\section{Background}

The human microbiota is comprised of bacteria, fungi, and viruses including bacteriophages, and is a very complex ecosystem that is in dynamic stability with each of its components and the host organism. Gut microbes colonize the majority of mucosal surfaces, and they play a primary role in host metabolism and are substantially involved in the development and normal action of the immune and neural systems, gastro-intestinal tract, and mucosal permeability $[1,2]$. The intestinal mucosa is a complex and extremely dynamic structure that readily adapts to a variety of signals that regulate intestinal permeability [3].

Intestinal barrier dysfunction or disruption, known as "leaky gut" syndrome, is characterized by the translocation of macromolecules, bacteria or their toxins to the lamina propria, which is implicated in the pathogenesis of numerous diseases [4]. Abnormally permeable mucosal barrier is associated with various pathologies including inflammatory bowel disease, Crohn's disease,

\footnotetext{
${ }^{*}$ Correspondence: georgetets@gmail.com

Human Microbiology Institute, 303 5th Avenue, Suite 2012, New York, NY 10016, USA
}

neurodegenerative diseases, diabetes type 1 , some types of cancers, cardiovascular disorders, rheumatoid arthritis, etc. [5-7]. It is currently known that the permeability of the mucosal barrier is regulated and influenced by numerous factors including the gut microbiota. Bacteria directly or indirectly modulate all components of intestinal permeability such as mucus integrity and trans- and paracellular transport [8].

Here, we evaluated the effect of primary lesions of the microbiota on intestinal permeability. To cause primary lesions of the microbiota, we used bacteriophages, which are believed to selectively interact with bacteria and to not affect eukaryotic cells $[9,10]$. The objective of this study was to assess the effect of microbiota treatment with bacteriophages on the intestinal permeability in vivo.

\section{Methods}

Group of five, healthy adult, male, albino Wistar rats were used. All experiments were performed in accordance with the guide for the care and use of laboratory animals.

Ethical approval was granted by the Human Microbiology Institute Ethics Committee (T-Ph2015). In accordance with ethical approval, consent to use human 
biological material was assumed following completion of consent forms.

The commercial Salmonella bacteriophage phage cocktail (Microgen, Russia) contains phages directed against Salmonella enterica serotypes: Paratyphi, Typhimurium, Heidelberg, Newport, Choleraesuis, Oranienburg, Infans, Dublin, Enteritidis, Anatum, and Newlands. Pyobacteriophage Polyvalent, another commercial phage cocktail (Microgen, Russia), contains phages directed against six pathogens: Staphylococcus aureus, Streptococcus pyogenes, Proteus mirabilis and P. vulgaris, Pseudomonas aeruginosa, Klebsiella pneumoniae, and Escherichia coli [36]. Phage cocktail $\left(1.5 \mathrm{ml}\left[1 \times 10^{6}\right.\right.$ plaque-forming units $/ \mathrm{ml}$ ] of each phage according to the manufacturer's instruction) was given daily to animals $(n=5)$ for 10 days. Each animal before bacteriophage challenge was used as its own control.

The lactulose:mannitol ratio was measured as a marker of intestinal permeability 2 days before and 10 days after phage challenge as described by Meddings et al. [11]. Lactulose (L7877, Sigma-Aldrich) and mannitol (M8429, Sigma-Aldrich) were utilized for all arms of the study. For permeability testing of both probes simultaneously, animals were fasted for $4 \mathrm{~h}$ and then gavaged with $120 \mathrm{mg}$ lactulose and $80 \mathrm{mg}$ mannitol in $2 \mathrm{ml}$ of water. Animals were placed in metabolic cages, and the urine passed over $24 \mathrm{~h}$ after the gavage was collected and assayed for the concentration of each probe by gas chromatography as described previously [12].

We measured serum circulating immune complexes (CIC) to evaluate possible systemic inflammatory response to the alterations caused by bacteriophage infection. Heparinized blood samples were collected at day 0 and day 10 from the tail vein of rats under sterile conditions. CIC were evaluated by sedimentation with a $4.0 \%$ polyethylene glycol solution followed by spectrophotometry as described by Ramos et al. [13]. The CIC concentration was evaluated as the difference between the values of the probes before and after bacteriophage challenge.

All results are reported as the mean \pm standard error (SE). Non-parametric paired Wilcoxon signed rank test was applied to analyze pre- and post-challenge differences. $P<0.05$ was considered significant.

\section{Results and discussion}

This study demonstrated that increased intestinal permeability may be induced by bacteriophages that affect the microbiota. We have previously confirmed the functionality and selectivity of bacteriophage cocktails (unpublished data). Ten days of administration of a bacteriophage cocktail active against Staphylococcus spp.,
Streptococcus spp., Proteus spp., Pseudomonas spp., E. coli, K. pneumonia, and Salmonella spp. did not lead to apparent clinical changes in the gastrointestinal tract or abnormal stool in rats. At the same time, all animals showed weight loss, messy hair, and decreased activity starting from the fifth day of the bacteriophage treatment, which are considered to be related to the translocation of endotoxins across leaky mucosa.

We performed a lactulose-mannitol permeability test to determine whether bacteriophages may cause microbiota diseases resulting in alterations in the host organism in the form of increased intestinal permeability [11]. Thus, we compared alterations of urinary mannitol and lactulose excretion and changes in the lactulose:mannitol ratio 2 days before and on the 10th day after daily challenge with the bacteriophage cocktail. The excretion of mannitol was slightly but not significantly reduced after bacteriophage challenge as compared to before. At the same time, rats exhibited a significant increase $(P<0,05)$ in lactulose excretion after bacteriophage treatment as compared to before treatment. The animals displayed a significantly elevated lactulose:mannitol ratio $(P<0.05)$, which was considered to reflect increased intestinal permeability (Fig. 1; Additional file 1: Table S1). The increase was at least 2,4-fold in all animals. All animals had a leaky gut with a benchmark lactulose/mannitol ratio $>0.46$ [12].

Next, we measured the serum concentrations of CIC to determine whether alterations caused by bacteriophages induced a systemic inflammatory reaction in the rats. The presence of $\mathrm{CIC}$ is an element of the normal immune response, and elevated levels of CIC are associated with different pathological conditions including intoxication [14]. As shown in Fig. 1, at the 10th day of treatment, the mean level of CIC was 2.5 times was higher than before treatment $(P<0.05)$, indicating endogenous intoxication, most likely caused by increased intestinal permeability and ongoing leaky gut. Untreated negative control animals that were kept under the same conditions as the treated animals did not show any changes over the study period (data not shown).

To our knowledge, this is the first study to indicate that experimental bacteriophage infection may be harmful for macro-organisms $[15,16]$. The pathological effect was revealed as increased intestinal permeability, and was a result of the phages' selective effect on the microbiota, without any direct effect on the host eukaryotic cells [17]. Over the last decade, the knowledge on abnormal intestinal permeability or leaky gut and increased bacterial translocation from the intestinal lumen has greatly progressed. This revealed the role of bacterial translocation as one of the main triggers in various poly-etiological diseases associated with chronic inflammation such 

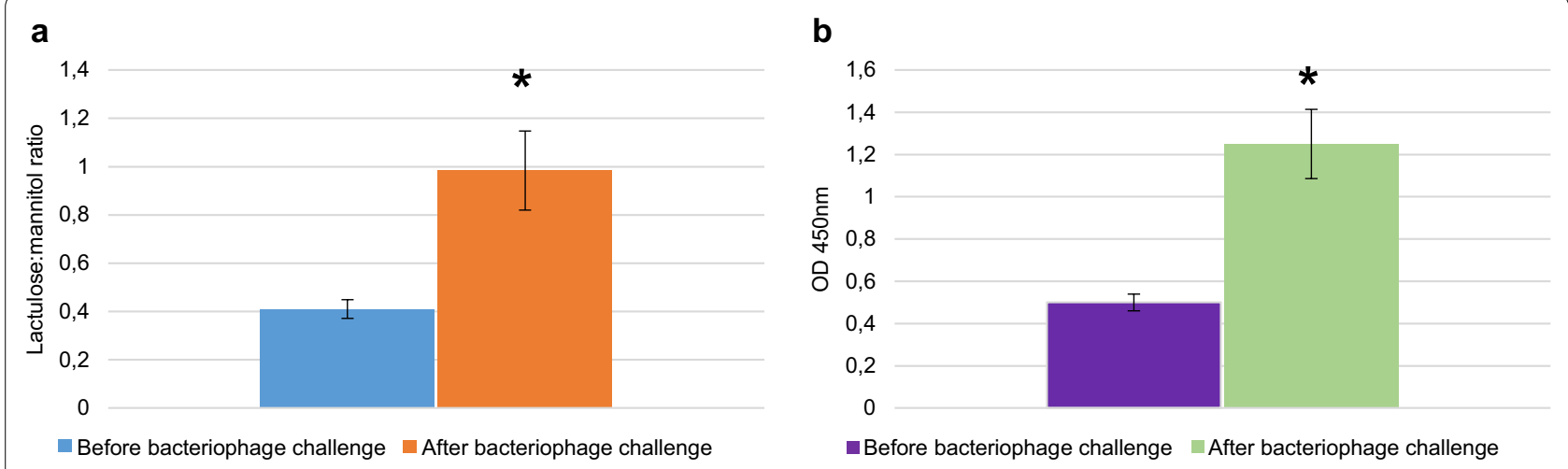

Fig. 1 Disruption of intestinal barrier integrity in rats treated with bacteriophage cocktail. a Changes in lactulose:mannitol ratio before and after treatment with the bacteriophage cocktail; $\mathbf{b}$ Serum concentrations of $\mathrm{ClC}$ before and after treatment with the bacteriophage cocktail. Data are expressed as the mean \pm SE. ${ }^{*} P<0.05$ (Wilcoxon signed-rank test). Data of the changes in lactulose and mannitol excretions after bacteriophage challenge in each animal are presented in Additional file 1: Table S1

as inflammatory bowel disease, Crohn's disease, Alzheimer's diseases, autism, diabetes, colonic neoplasia, heart failure, arrhythmias, rheumatoid arthritis, etc. [2, 5-7]. Our findings indicate that bacteriophages, which were previously not considered mammalian or human pathogens, can promote microbiota diseases and thus indirectly cause pathological conditions of mammals that are associated with leaky gut. These pathologies are believed not to be contagious or, at least, there currently is no reliable proof-of-concept of them being contagious $[18,19]$. However, taking into consideration their possible association with leaky gut, it can be assumed that their incidence and distribution may be caused by phages originating from the outer environment, because bacteriophages are widely spread and humans are constantly exposed to them [20]. Finally, infection of the microbiota by bacteriophages can be considered a new group of viral diseases of mammals. Additional studies should be conducted, including those using germ-free rats as controls to confirm the effect of the bacteriophage on the gut microbiota and employing metagenomic analyses of the changes in the gut microbial communities due to the bacteriophages, leading to a leaky gut.

Further studies will be necessary to unravel microbiota diseases and to evaluate their underlying mechanisms and roles in different human pathologies.

\section{Additional file}

Additional file 1: Table S1. Changes in lactulose and mannitol excretions after bacteriophage challenge.

\section{Abbreviation}

CIC: circulating immune complexes.

\section{Authors' contributions}

VT, GT: conceived, designed experiments and performed experiments, contributed reagents, materials, and analysis tools. GT: analyzed the data. GT: helped draft the manuscript. Both authors read and approved the final manuscript.

\section{Acknowledgements}

We thank prof. A. Kaufman for his assistance in completing the project.

\section{Availability of supporting data}

The dataset supporting the conclusions of this article is included within the article (and its Additional file 1).

\section{Competing interests}

The authors declare that they have no competing interests.

\section{Funding information}

This research received no specific grant from any funding agency in the public, commercial, or not-for-profit sectors.

Received: 21 March 2016 Accepted: 19 May 2016

Published online: 23 June 2016

\section{References}

1. Nusrat A, Turner JR, Madara JL. Regulation of tight junctions by extracellular stimuli: nutrients, cytokines, and immune cells. Am J Physiol Gastrointest Liver Physiol. 2000;279:G851-7.

2. Borre YE, O'Keeffe GW, Clarke G, Stanton C, Dinan TG, Cryan JF. Microbiota and neurodevelopmental windows: implications for brain disorders. Trends Mol Med. 2014;20:509-18.

3. Peterson LW, Artis D. Intestinal epithelial cells: regulators of barrier function and immune homeostasis. Nat Rev Immunol. 2014;14:141-53.

4. Maes M, Kubera M, Leunis JC, Berk M. Increased IgA and IgM responses against gut commensals in chronic depression: further evidence for increased bacterial translocation or leaky gut. J Affect Disord. 2012;141:55-62.

5. Tlaskalova-Hogenová H, Stepankova R, Kozakova H, Hudcovic T, Vannucci L, Tuckova L, Rossmann P, Hrncir T, Kverka M, Zakostelska Z, Klimesova K, Pribylova J, Bartova J, Sanchez D, Fundova P, Borovska D, Srutkova D, Zidek Z, Schwarzer M, Drastich P, Funda D. The role of gut microbiota (commensal bacteria) and the mucosal barrier in the pathogenesis of inflammatory and autoimmune diseases and cancer: contribution of 
germ-free and gnotobiotic animal models of human diseases. Cell Mol Immunol. 2011;8:110-20.

6. Berk M, Williams $\sqcup$, Jacka FN, O'Neil A, Pasco JA, Moylan S, Allen NB, Stuart AL, Hayley AC, Byrne ML, Maese M. So depression is an inflammatory disease, but where does the inflammation come from? BMC Med. 2013; doi:10.1186/1741-7015-11-200.

7. Anderson G, Maes M. The gut-brain axis: the role of melatonin in linking psychiatric, inflammatory and neurodegenerative conditions. Adv Integr Med. 2015;2:31-7.

8. Ashida H, Ogawa M, Kim M, Mimuro H, Sasakaw C. Bacteria and host interactions in the gut epithelial barrier. Nat Chem Biol. 2012;8:36-45.

9. Wittebole X, De Roock S, Opal SM. A historical overview of bacteriophage therapy as an alternative to antibiotics for the treatment of bacterial pathogens. Virulence. 2014;5:226-35.

10. Fischetti VA. Bacteriophage lytic enzymes: novel anti-infectives. Trends Microbiol. 2005;13:491-6.

11. Meddings JB, Swain MG. Environmental stress-induced gastrointestinal permeability is mediated by endogenous glucocorticoids in the rat. Gastroenterology. 2000;119:1019-28.

12. Keshavarzian A, Fields JZ, Vaeth J, Holmes EW. The differing effects of acute and chronic alcohol on gastric and intestinal permeability. Am J Gastroenterol. 1994:89:2205-11.

13. Ramos GS, Bottasso OA, Morini JC, Segal-Eiras A. Evaluation of circulating immune complexes in leprosy. Rev Argent Microbiol. 1987;20:163-70.

14. Schietroma M, Pessia B, Carlei F, Cecilia EM, Amicucci G. Intestinal permeability, systemic endotoxemia, and bacterial translocation after open or laparoscopic resection for colon cancer: a prospective randomized study. Int J Colorectal Dis. 2013;28:1651-60.

15. Sarker SA, McCallinb S, Barrettob C, Bergerb B, Pittetb AC, Sultanaa S, Krauseb L, Huqa S, Bibilonib R, Bruttinb A, Reutelerb G, Brussowb H. Oral T4-like phage cocktail application to healthy adult volunteers from Bangladesh. Virology. 2012;434:222-32.

16. Yilmaz C, Colak M, Yilmaz BC, Ersoz G, Kutateladze M, Gozlugol M. Bacteriophage Therapy in Implant-Related Infections. J Bone Joint Surg Am. 2013;95:117-25.

17. Dabrowska K, Switała-Jelen K, Opolski A, Weber-Dabrowska B, Gorski A. Bacteriophage penetration in vertebrates. J Appl Microbiol. 2005:98:7-13.

18. Jaunmuktane Z, Mead S, Ellis M, Wadsworth JDF, Nicoll AJ, Kenny J, Launchbury F, Linehan J, Richard-Loendt A, Walker AS, Rudge P, Collinge $J$, Brandner $S$. Evidence for human transmission of amyloid- $\beta$ pathology and cerebral amyloid angiopathy. Nature. 2015;525:247-50.

19. Welsh JS. Contagious cancer. Oncologist. 2011;16:1-4.

20. De Paepe M, Leclerc M, Tinsley CR, Petit MA. Bacteriophages: an underestimated role in human and animal health. Front Cell Infect Microbiol. 2014;. doi:10.3389/fcimb.2014.00039.

\section{Submit your next manuscript to BioMed Central and we will help you at every step:}

- We accept pre-submission inquiries

- Our selector tool helps you to find the most relevant journal

- We provide round the clock customer support

- Convenient online submission

- Thorough peer review

- Inclusion in PubMed and all major indexing services

- Maximum visibility for your research

Submit your manuscript at www.biomedcentral.com/submit 